\title{
Prognostic Value of a Nomogram Based on the Dynamic Albumin-to-Alkaline Phosphatase Ratio for Patients with Extensive-Stage Small-Cell Lung
} Cancer

This article was published in the following Dove Press journal:

OncoTargets and Therapy

\section{Butuo $\mathrm{Li}^{1}$ \\ Chao Jiang ${ }^{2}$ \\ Ruiqing Wang ${ }^{3}$ \\ Bing Zou' \\ Peng Xie $\mathbb{1}^{\prime}$ \\ Wanlong $\mathrm{Li}^{1}$ \\ Xindong Sun' \\ Jinming $\mathrm{Yu}^{\prime}$ \\ Linlin Wang $\mathbb{B D}^{\prime}$}

'Department of Radiation Oncology, Shandong Cancer Hospital and Institute, Shandong First Medical University and Shandong Academy of Medical Sciences, Jinan 250017, Shandong Province, People's Republic of China; ${ }^{2}$ Department of Otorhinolaryngology, Head and Neck Surgery, Shandong Provincial Hospital Affiliated to Shandong First Medical University, Jinan, Shandong Province 25002I, People's Republic of China; ${ }^{3}$ Department of Breast Surgery, Linyi People's Hospital, Linyi 276000, Shandong Province, People's Republic of China
Correspondence: Linlin Wang

Tel +86-53I-67626I42

Fax +86-53I-67626I4I

Email wanglinlinatjn@163.com
Purpose: Small-cell lung cancer (SCLC) is known as the characteristics of high invasion, rapid progression, and poor prognosis. Therefore, identification of patients with high risk of progression and death is critical to improve the survival of patients with extensive-stage SCLC (ES-SCLC). This study was designed to determine the prognostic importance of the albumin-to-alkaline phosphatase ratio (AAPR) in the survival of patients with ESSCLC and to develop a nomogram based on AAPR dynamics for ES-SCLC prognosis.

Patients and Methods: Characteristics were reviewed from 300 patients with ES-SCLC. Training and validation cohorts included 200 and 100 patients, respectively. We applied univariate and multivariate Cox models to assess the prognostic value of AAPR for ESSCLC. The nomogram for progression-free survival (PFS) and overall survival (OS) of ESSCLC patients was developed based on the multivariate survival analysis of the training cohort. External validation of the established nomogram was performed using the validation cohort.

Results: N3 stage, thoracic radiotherapy, and post-AAPR were the independent factors identified for PFS. T stage, thoracic radiotherapy, and high post-AAPR were the independent risk factors identified for death. The prognostic nomogram was established by integrating the independent significant factors for PFS and OS in the training cohort with the c-indices of 0.675 and 0.662 , respectively, and validated in the validation cohort. The nomogram had superior prognosis prediction ability than did TNM stage. Decision curve analysis (DCA) also indicated clinical net benefits from the nomogram.

Conclusion: AAPR was valuable for prognosis prediction in patients with ESSCLC and was recommended to be dynamically evaluated to guide patient treatment. Additionally, the nomogram covering post-AAPR accurately predicted individual survival probability.

Keywords: extensive-stage small-cell lung cancer; ES-SCLC, albumin-to-alkaline phosphatase ratio; AAPR, dynamic, nomogram, prognosis prediction

\section{Introduction}

Small-cell lung cancer (SCLC) accounts for $10-15 \%$ of all lung cancer cases, ${ }^{1}$ and about $70 \%$ of patients with SCLC are in the extensive stage (ES). ${ }^{2}$ The application of targeted therapy and immunotherapy have greatly improved survival in patients with NSCLC. ${ }^{3,4}$ However, it is disappointing that the search for SCLC target drugs has been unsuccessful. ${ }^{5}$ Improvements in progression-free survival (PFS) and 
overall survival (OS) of 1.1 and 2 months, respectively, have been achieved by the additional application of atezolizumab in ES-SCLC patients, ${ }^{6}$ yet platinum-based chemotherapy (platinum/etoposide) for 4-6 cycles is regarded as the first-line standard treatment for ES-SCLC. ${ }^{7}$ Despite high initial response rates to first-line chemotherapy of $67 \%$ to $80 \%,{ }^{8}$ patients with ES-SCLC usually experience disease relapse and distant metastasis within a short timeframe, because of the extensive invasiveness property of the disease. Disease progression also occurs in patients who have not finished the planned treatment. ${ }^{8}$ Therefore, the identification of patients with a high risk of progression and death is crucial for the individualized management and improvement of patient survival in patients with ES-SCLC.

Nutritional status and inflammation of patients play vital roles in carcinogenesis and prognosis of SCLC., ${ }^{9,10}$ A decreased albumin (ALB) level is regarded as a surrogate parameter for malnutrition and systemic inflammation, which are negative indicators for cancer patients. ${ }^{10}$ Serum ALB is a reliable factor for survival of patients with tumors including those arising from colorectal cancer, ${ }^{11}$ lung cancer, ${ }^{12}$ breast cancer, ${ }^{13}$ and gastric cancer. ${ }^{14}$ Previous studies have found that pathological elevation of alkaline phosphatase (ALP) is usually associated with liver and kidney disease or bone metastasis. ${ }^{15-17}$ Interestingly, ALP plays a role in tumor growth, is closely associated with inflammation, ${ }^{18,19}$ and is regarded as a prognostic factor for SCLC patients.

Increasing amounts of evidence show the superiority of combined indices over simple markers for survival prediction, likely because of tumor heterogeneity and complexity. ${ }^{20}$ The incorporated index of albumin-toalkaline phosphatase ratio (AAPR) has prognostic value in hepatocellular carcinoma and nasopharyngeal carcinoma, and was more powerful than simple ALB or ALP. $^{21,22}$ However, the systemic and tumor status is dynamic during tumor development and treatment. Previous studies have mostly focused on baseline parameters as prognostic markers and have ignored the value of dynamic AAPR, which might be more informative and precise. ${ }^{21,22}$ The prognostic ability and complementary value of dynamic AAPR to TNM stage for the survival of patients with ES-SCLC remains unclear.

TNM stage, the traditional prognostic factor for patients with malignant tumors, only represents tumor burden. ${ }^{23}$ Recently, integration of AAPR with the TNM staging system was shown to have superior predictive accuracy to TNM stage alone. ${ }^{21}$ Nomograms, graphic illustrations of a statistical model, have been developed in lung, ${ }^{24}$ breast, ${ }^{25}$ and other cancers ${ }^{26}$ for prognosis estimation. Importantly, the nomogram based on clinicopathological characteristics could predict the survival of cancer patients more accurately than could the TNM staging system. Thus, nomograms based on dynamic AAPR might be able to provide individualized prognostic estimations in ES-SCLC patients to optimize treatment approaches.

This study was designed to analyze the prognostic value of dynamic AAPR in ES-SCLC patients, and to establish and validate nomogram based on dynamic AAPR for prognosis of ES-SCLC.

\section{Patients and Methods Study Population}

We reviewed medical record of patients diagnosed with ES-SCLC according to the Veterans Administration Lung Study Group (VALSG) staging system in Shandong Cancer Hospital from January 2013 to May 2018. Patients who met the following criteria were enrolled in the study: 1) pathological diagnosis of SCLC; 2) imaging diagnosis of ES-SCLC; 3) cisplatin/etoposide as first-line treatment was tolerated well; and 4) available medical records. Exclusion criteria were: 1) patients who were initially diagnosed as limited-stage SCLC (LS-SCLC) and progressed to ES-SCLC; and 2) other primary cancers diagnosed before or after SCLC. Finally, 300 patients with ES-SCLC were included, 200 of which were used as the training cohort, and the remaining 100 were used as the validation cohort. Our study was performed in accordance with the principles of the 1975 Declaration of Helsinki and its later amendments or comparable ethical standards, and was approved by the Ethics Committee of Shandong Cancer Hospital (No. SDTHEC201808005). Due to the retrospective nature of the study and the fact that no case details were shown, informed consent was waived by the Ethics Committee of Shandong Cancer Hospital. All data was kept confidential.

\section{Data Collection}

All data were collected using uniform database templates to ensure consistency. The medical records of all patients were reviewed with respect to laboratory serum ALB and ALP, and the clinical factors, including age, gender, body mass index (BMI) at diagnosis (calculated by weight and 
Table I Patients Characteristics in Training Cohort and Validation Cohort

\begin{tabular}{|c|c|c|c|}
\hline \multirow[t]{2}{*}{ Variables } & \multicolumn{2}{|c|}{ No. of Patients (\%) } & \multirow[t]{2}{*}{ p-value } \\
\hline & $\begin{array}{l}\text { Training } \\
\text { Cohort }\end{array}$ & $\begin{array}{l}\text { Validation } \\
\text { Cohort }\end{array}$ & \\
\hline $\begin{array}{l}\text { Age } \\
\qquad<60 \\
\geq 60\end{array}$ & $\begin{array}{l}100(50 \%) \\
100(50 \%)\end{array}$ & $\begin{array}{l}43(43 \%) \\
57(57 \%)\end{array}$ & 0.25 \\
\hline $\begin{array}{l}\text { Sex } \\
\qquad \text { Male } \\
\text { Female }\end{array}$ & $\begin{array}{l}157(78.1 \%) \\
43(21.4 \%)\end{array}$ & $\begin{array}{l}73(73 \%) \\
27(27 \%)\end{array}$ & 0.29 \\
\hline $\begin{array}{l}\text { Marital } \\
\text { Married } \\
\text { Unmarried }\end{array}$ & $\begin{array}{l}193(96.5 \%) \\
7(3.5 \%)\end{array}$ & $\begin{array}{l}97(97 \%) \\
3(3 \%)\end{array}$ & 0.82 \\
\hline $\begin{array}{l}\text { BMI } \\
\qquad \begin{array}{l}\text { BMI }<18.5 \\
\mid 8.5 \geq \mathrm{BMI}<25 \\
\text { BMI } \geq 25\end{array}\end{array}$ & $\begin{array}{l}10(5 \%) \\
116(58 \%) \\
75(37 \%)\end{array}$ & $\begin{array}{l}3(3 \%) \\
59(59 \%) \\
38(38 \%)\end{array}$ & 0.72 \\
\hline $\begin{array}{l}\text { Smoking History } \\
\text { No } \\
\text { Yes }\end{array}$ & $\begin{array}{l}68(34 \%) \\
132(66 \%)\end{array}$ & $\begin{array}{l}39(39 \%) \\
61 \text { (6I\%) }\end{array}$ & 0.39 \\
\hline $\begin{array}{l}\text { Smoking Index } \\
\quad<800 \\
\geq 800\end{array}$ & $\begin{array}{l}126(63 \%) \\
74(37 \%)\end{array}$ & $\begin{array}{l}62(62 \%) \\
38(38 \%)\end{array}$ & 0.87 \\
\hline $\begin{array}{l}\text { KPS } \\
\qquad 90 \\
<90\end{array}$ & $\begin{array}{l}\text { II } 4(57 \%) \\
86(43 \%)\end{array}$ & $\begin{array}{l}66(66 \%) \\
34(34 \%)\end{array}$ & 0.13 \\
\hline $\begin{array}{l}\text { T Stage } \\
\text { TI-T2 } \\
\text { T3-T4 }\end{array}$ & $\begin{array}{l}82(41 \%) \\
118(59 \%)\end{array}$ & $\begin{array}{l}4 I \text { (4I\%) } \\
59 \text { (59\%) }\end{array}$ & 0.99 \\
\hline $\begin{array}{l}\text { N Stage } \\
\text { N0-N2 } \\
\text { N3 }\end{array}$ & $\begin{array}{l}103(51.5 \%) \\
97(48.5 \%)\end{array}$ & $\begin{array}{l}52(52 \%) \\
48(58 \%)\end{array}$ & 0.94 \\
\hline $\begin{array}{l}\text { Brain Metastasis } \\
\text { No } \\
\text { Yes }\end{array}$ & $\begin{array}{l}138(69 \%) \\
62(31 \%)\end{array}$ & $\begin{array}{l}78 \text { (78\%) } \\
22(22 \%)\end{array}$ & 0.10 \\
\hline $\begin{array}{l}\text { Liver Metastasis } \\
\text { No } \\
\text { Yes }\end{array}$ & $\begin{array}{l}138(69 \%) \\
62(31 \%)\end{array}$ & $\begin{array}{l}70(70 \%) \\
30(30 \%)\end{array}$ & 0.6 \\
\hline $\begin{array}{l}\text { Bone Metastasis } \\
\text { No } \\
\text { Yes }\end{array}$ & $\begin{array}{l}138(69 \%) \\
62(31 \%)\end{array}$ & $\begin{array}{l}66(66 \%) \\
34(34 \%)\end{array}$ & 0.86 \\
\hline $\begin{array}{l}\text { Thoracic Radiotherapy } \\
\text { No } \\
\text { Yes }\end{array}$ & $\begin{array}{l}137(68.5 \%) \\
63(31.5 \%)\end{array}$ & $\begin{array}{l}64(64 \%) \\
36(36 \%)\end{array}$ & 0.44 \\
\hline
\end{tabular}

(Continued)
Table I (Continued).

\begin{tabular}{|c|l|l|l|}
\hline \multirow{2}{*}{ Variables } & \multicolumn{2}{|l|}{ No. of Patients (\%) } & \multirow{2}{*}{ p-value } \\
\cline { 2 - 3 } & $\begin{array}{l}\text { Training } \\
\text { Cohort }\end{array}$ & $\begin{array}{l}\text { Validation } \\
\text { Cohort }\end{array}$ & \\
\hline $\begin{array}{c}\text { Pre-ALB } \\
\leq 40 \\
>40\end{array}$ & $56(28 \%)$ & $36(36 \%)$ & 0.16 \\
\hline $\begin{array}{c}\text { Pre-ALP } \\
\leq 100\end{array}$ & $144(72 \%)$ & $64(64 \%)$ & \\
$>100$ & $89(44.5 \%)$ & $36(36 \%)$ & 0.16 \\
\hline $\begin{array}{c}\text { Pre-AAPR } \\
\leq 0.52 \\
>0.52\end{array}$ & $111(55.5 \%)$ & $64(64 \%)$ & \\
\hline $\begin{array}{c}\text { Post-ALB } \\
\leq 40\end{array}$ & $\begin{array}{l}126(63 \%) \\
>40\end{array}$ & $\begin{array}{l}61(61 \%) \\
39(39 \%)\end{array}$ & \\
\hline $\begin{array}{c}\text { Post-ALP } \\
\leq 100 \\
>100\end{array}$ & $\begin{array}{l}65(32.5 \%) \\
135(67.5 \%)\end{array}$ & $\begin{array}{l}22(22 \%) \\
78(78 \%)\end{array}$ & \\
\hline $\begin{array}{c}\text { Post-AAPR } \\
\leq 0.52 \\
>0.52\end{array}$ & $145(72.5 \%)$ & $72(72 \%)$ & 0.05 \\
\hline
\end{tabular}

Abbreviations: KPS, Karnofsky performance score; BMI, body mass index; AAPR, albumin-to-alkaline phosphatase ratio.

height), marital status (married and unmarried [which included single, divorced, and widowed]), smoking history and index, Karnofsky performance score (KPS), TNM stage, brain, liver and bone metastasis, and thoracic radiotherapy. Pre-ALB and pre-ALP were defined as the serum ALB and ALP levels before treatment, respectively. PostALB and post-ALP were defined as the serum ALB and ALP levels, respectively, after planned therapy for patients without progression during systemic treatment, and after progression for patients with progression before the end of planned systemic therapy. AAPR was calculated as the ratio of absolute ALB to absolute ALP.

Tumor response was assessed based on the Response Evaluation Criteria in Solid Tumors (RECIST) version 1.1. PFS and OS were defined from the date of initial diagnosis to the date of progression and the date of death or the last follow-up, respectively. PFS data were collected from medical records, and OS data were obtained through telephone follow-up. 
Table 2 Correlation Between AAPR and Patient Characteristics in Training Cohort

\begin{tabular}{|c|c|c|c|c|c|c|}
\hline & Pre-AAPR $\leq 0.52$ & Pre-AAPR $>0.52$ & p-value & Post-AAPR $\leq 0.52$ & Post-AAPR $>0.52$ & p-value \\
\hline $\begin{array}{l}\text { Age } \\
\qquad 60 \\
\geq 60\end{array}$ & $\begin{array}{l}63(50 \%) \\
63(50 \%)\end{array}$ & $\begin{array}{l}37(50 \%) \\
37(50 \%)\end{array}$ & 0.99 & $\begin{array}{l}47(44.8 \%) \\
58(55.2 \%)\end{array}$ & $\begin{array}{l}53(55.8 \%) \\
42(44.2 \%)\end{array}$ & 0.12 \\
\hline $\begin{array}{l}\text { Sex } \\
\qquad \begin{array}{l}\text { Male } \\
\text { Female }\end{array}\end{array}$ & $\begin{array}{l}102(81 \%) \\
24(19 \%)\end{array}$ & $\begin{array}{l}55(74.3 \%) \\
19(25.7 \%)\end{array}$ & 0.27 & $\begin{array}{l}84(80 \%) \\
21(20 \%)\end{array}$ & $\begin{array}{l}73(76.8 \%) \\
22(23.2 \%)\end{array}$ & 0.59 \\
\hline $\begin{array}{l}\text { Marital } \\
\text { Married } \\
\text { Unmarried }\end{array}$ & $\begin{array}{l}\text { I20 (95.2\%) } \\
6(4.8 \%)\end{array}$ & $\begin{array}{l}73 \text { (98.6\%) } \\
\text { I (1.4\%) }\end{array}$ & 0.21 & $\begin{array}{l}100(95.2 \%) \\
5(4.8 \%)\end{array}$ & $\begin{array}{l}93(97.9 \%) \\
2(2.1 \%)\end{array}$ & 0.31 \\
\hline $\begin{array}{l}\text { BMI } \\
\qquad \begin{array}{l}\text { BMI }<18.5 \\
\mid 8.5 \geq \text { BMI } \mid<25 \\
\text { BMI } \geq 25\end{array}\end{array}$ & $\begin{array}{l}6(4.8 \%) \\
76(60.3 \%) \\
44(34.9 \%)\end{array}$ & $\begin{array}{l}3(4.1 \%) \\
41(55.4 \%) \\
30(40.5 \%)\end{array}$ & 0.73 & $\begin{array}{l}5(4.8 \%) \\
66(62.8 \%) \\
34(32.4 \%)\end{array}$ & $\begin{array}{l}4(4.2 \%) \\
51(53.7 \%) \\
40(42.1 \%)\end{array}$ & 0.36 \\
\hline $\begin{array}{l}\text { Smoking History } \\
\text { No } \\
\text { Yes }\end{array}$ & $\begin{array}{l}42(33.3 \%) \\
84(66.7 \%)\end{array}$ & $\begin{array}{l}26(35.1 \%) \\
48(64.9 \%)\end{array}$ & 0.80 & $\begin{array}{l}33(31.4 \%) \\
72(68.6 \%)\end{array}$ & $\begin{array}{l}35(36.8 \%) \\
60(63.2 \%)\end{array}$ & 0.85 \\
\hline $\begin{array}{l}\text { Smoking Index } \\
\quad<800 \\
\geq 800\end{array}$ & $\begin{array}{l}80(63.5 \%) \\
46(36.5 \%)\end{array}$ & $\begin{array}{l}46(62.2 \%) \\
28(37.8 \%)\end{array}$ & 0.85 & $\begin{array}{l}64(61 \%) \\
41 \text { (39\%) }\end{array}$ & $\begin{array}{l}62(65.3 \%) \\
33(34.7 \%)\end{array}$ & 0.53 \\
\hline $\begin{array}{l}\text { KPS } \\
\qquad 990 \\
<90\end{array}$ & $\begin{array}{l}66(52.4 \%) \\
60(47.6 \%)\end{array}$ & $\begin{array}{l}48(66 \%) \\
26(34 \%)\end{array}$ & 0.085 & $\begin{array}{l}63(60 \%) \\
42(40 \%)\end{array}$ & $\begin{array}{l}51(53.7 \%) \\
44(46.3 \%)\end{array}$ & 0.37 \\
\hline $\begin{array}{l}\text { T Stage } \\
\text { TI-T2 } \\
\text { T3-T4 }\end{array}$ & $\begin{array}{l}47(33.3 \%) \\
79(62.7 \%)\end{array}$ & $\begin{array}{l}35(62.7 \%) \\
39(52.7 \%)\end{array}$ & 0.17 & $\begin{array}{l}37(35.2 \%) \\
68(64.8 \%)\end{array}$ & $\begin{array}{l}45(47.4 \%) \\
50(52.6 \%)\end{array}$ & 0.082 \\
\hline $\begin{array}{l}\text { N Stage } \\
\text { N0-N2 } \\
\text { N3 }\end{array}$ & $\begin{array}{l}60(47.6 \%) \\
66(52.4 \%)\end{array}$ & $\begin{array}{l}43(52.4 \%) \\
31(41.9 \%)\end{array}$ & 0.15 & $\begin{array}{l}57(54.3 \%) \\
48(45.7 \%)\end{array}$ & $\begin{array}{l}46(48.4 \%) \\
49(51.6 \%)\end{array}$ & 0.41 \\
\hline $\begin{array}{l}\text { Brain Metastasis } \\
\text { No } \\
\text { Yes }\end{array}$ & $\begin{array}{l}89(70.6 \%) \\
37(29.4 \%)\end{array}$ & $\begin{array}{l}49(66.2 \%) \\
25(33.8 \%)\end{array}$ & 0.51 & $\begin{array}{l}74(70.5 \%) \\
31(29.5 \%)\end{array}$ & $\begin{array}{l}64(67.4 \%) \\
31(32.6 \%)\end{array}$ & 0.64 \\
\hline $\begin{array}{l}\text { Liver Metastasis } \\
\text { No } \\
\text { Yes }\end{array}$ & $\begin{array}{l}78 \text { (6I.9\%) } \\
48 \text { (38.1\%) }\end{array}$ & $\begin{array}{l}60(81.1 \%) \\
14(18.9 \%)\end{array}$ & 0.005 & $\begin{array}{l}68 \text { (64.8\%) } \\
37 \text { (35.2\%) }\end{array}$ & $\begin{array}{l}7 \mathrm{I}(73.7 \%) \\
24 \text { (26.3\%) }\end{array}$ & 0.17 \\
\hline $\begin{array}{l}\text { Bone Metastasis } \\
\text { No } \\
\text { Yes }\end{array}$ & $\begin{array}{l}81(64.3 \%) \\
45(35.7 \%)\end{array}$ & $\begin{array}{l}57(77 \%) \\
17(23 \%)\end{array}$ & 0.06 & $\begin{array}{l}72(68.6 \%) \\
33(31.4 \%)\end{array}$ & $\begin{array}{l}66(69.5 \%) \\
29(30.5 \%)\end{array}$ & 0.89 \\
\hline $\begin{array}{l}\text { Thoracic Radiotherapy } \\
\text { No } \\
\text { Yes }\end{array}$ & $\begin{array}{l}90(71.4 \%) \\
36(28.6 \%)\end{array}$ & $\begin{array}{l}47(63.5 \%) \\
27(36.5 \%)\end{array}$ & 0.25 & $\begin{array}{l}74(70.5 \%) \\
31 \text { (29.5\%) }\end{array}$ & $\begin{array}{l}63(66.3 \%) \\
32(33.7 \%)\end{array}$ & 0.53 \\
\hline
\end{tabular}

Abbreviations: KPS, Karnofsky performance score; BMI, body mass index; AAPR, albumin-to-alkaline phosphatase ratio.

\section{Statistical Analysis}

BMI was used to categorize patients into clinical groupings of less than $18.5 \mathrm{~kg} / \mathrm{m}^{2}$ (underweight), $18.5-25 \mathrm{~kg} / \mathrm{m}^{2}$ (normal weight), greater than $25 \mathrm{~kg} / \mathrm{m}^{2}$ (overweight). The ALB and ALP cut-off values were set as $40 \mathrm{~g} / \mathrm{L}$ and 100 $\mathrm{U} / \mathrm{L}$, respectively, which represent the lower normal limit 
Table 3 Univariate and Multivariate Cox Models for PFS in Training Cohort

\begin{tabular}{|c|c|c|c|c|c|c|}
\hline Variables & Uni HR & $95 \% \mathrm{Cl}$ & p-value & Multi HR & $95 \% \mathrm{Cl}$ & p-value \\
\hline \multicolumn{7}{|l|}{ Age } \\
\hline$<60$ & 1 & & & & & \\
\hline$\geq 60$ & 0.98 & $0.73-1.31$ & 0.87 & & & \\
\hline \multicolumn{7}{|l|}{ Marital } \\
\hline Married & 1 & & & & & \\
\hline Unmarried & 1.29 & $0.57-2.93$ & 0.54 & & & \\
\hline \multicolumn{7}{|l|}{ BMI } \\
\hline $\mathrm{BMI}<18.5$ & 1 & & & & & \\
\hline$|8.5 \geq \mathrm{BM}|<25$ & 1.21 & $0.56-2.61$ & & & & \\
\hline $\mathrm{BMI} \geq 25$ & 1.04 & $0.47-2.25$ & 0.55 & & & \\
\hline \multicolumn{7}{|l|}{ Sex } \\
\hline Male & 1 & & & & & \\
\hline Female & 0.78 & $0.54-1.12$ & 0.17 & & & \\
\hline \multicolumn{7}{|l|}{ Smoking History } \\
\hline No & I & & & & & \\
\hline Yes & 1.08 & $0.79-1.47$ & 0.64 & & & \\
\hline \multicolumn{7}{|l|}{ Smoking Index } \\
\hline$<800$ & I & & & & & \\
\hline$\geq 800$ & 1.16 & $0.86-1.57$ & 0.33 & & & \\
\hline \multicolumn{7}{|l|}{ KPS } \\
\hline$\geq 90$ & 1 & & & & & \\
\hline$<90$ & 1.03 & $0.76-1.39$ & 0.85 & & & \\
\hline \multicolumn{7}{|l|}{ T Stage } \\
\hline TI-T2 & 1 & & & 1 & & \\
\hline T3-T4 & 1.40 & $1.03-1.91$ & 0.03 & 1.33 & $0.95-1.85$ & 0.097 \\
\hline \multicolumn{7}{|l|}{ N Stage } \\
\hline No-N2 & 1 & & & I & & \\
\hline N3 & 1.62 & $1.20-2.20$ & 0.002 & 1.41 & $1.03-1.93$ & 0.034 \\
\hline \multicolumn{7}{|l|}{ Brain Metastasis } \\
\hline No & 1 & & & & & \\
\hline Yes & 0.98 & $0.7 \mid-1.35$ & 0.90 & & & \\
\hline \multicolumn{7}{|l|}{ Liver Metastasis } \\
\hline No & I & & & & & \\
\hline Yes & 1.31 & $0.95-1.79$ & 0.095 & & & \\
\hline \multicolumn{7}{|l|}{ Bone Metastasis } \\
\hline No & I & & & & & \\
\hline Yes & 1.07 & $0.78-1.47$ & 0.66 & & & \\
\hline \multicolumn{7}{|c|}{ Thoracic Radiotherapy } \\
\hline No & 1 & & & I & & \\
\hline Yes & 0.40 & $0.29-0.56$ & $<0.001$ & 0.40 & $0.29-0.56$ & $<0.001$ \\
\hline \multicolumn{7}{|l|}{ Pre-ALB } \\
\hline$\leq 40$ & 1 & & & & & \\
\hline$>40$ & 0.85 & $0.61-1.18$ & 0.33 & & & \\
\hline
\end{tabular}

(Continued) 
Table 3 (Continued).

\begin{tabular}{|c|c|c|c|c|c|c|}
\hline Variables & Uni HR & $95 \% \mathrm{Cl}$ & p-value & Multi HR & $95 \% \mathrm{Cl}$ & p-value \\
\hline \multicolumn{7}{|l|}{ Pre-ALP } \\
\hline$\leq 100$ & I & & & & & \\
\hline$>100$ & 1.22 & $0.90-1.65$ & 0.20 & & & \\
\hline \multicolumn{7}{|l|}{ Pre-AAPR } \\
\hline$\leq 0.52$ & I & & & & & \\
\hline$>0.52$ & 0.21 & $0.50-0.95$ & 0.021 & & & \\
\hline \multicolumn{7}{|l|}{ Post-ALB } \\
\hline$\leq 40$ & I & & & & & \\
\hline$>40$ & 0.60 & $0.60-1.12$ & 0.21 & & & \\
\hline \multicolumn{7}{|l|}{ Post-ALP } \\
\hline$\leq 100$ & 1 & & & & & \\
\hline$>100$ & 1.39 & $1.00-1.93$ & 0.049 & & & \\
\hline \multicolumn{7}{|l|}{ Post-AAPR } \\
\hline$\leq 0.52$ & I & & & I & & \\
\hline$>0.52$ & 0.61 & $0.45-0.82$ & 0.001 & 0.67 & $0.49-0.92$ & 0.013 \\
\hline
\end{tabular}

Abbreviations: AAPR, albumin-to-alkaline phosphatase ratio; BMI, body mass index; HR, hazard ratios; KPS, Karnofsky performance score; PFS, progression-free survival.

of ALB and upper normal limit of ALP. Receiver operating characteristic curve (ROC) was used to determine the optimal AAPR cut-off value of 0.52 , by setting OS as the state variable. Patients in training and validation cohorts were dichotomized into low and high groups according to the cut-off values. The difference in variables between the training and validation cohorts was evaluated using the chi-square test. The chi-square test was also used to assess the association between AAPR and patient characteristics. We applied univariate and multivariate Cox models to assess the independent prognostic values for PFS and OS in ES-SCLC. Variables with $\mathrm{p}<0.1$ in univariate analyses were included in multivariate Cox analyses. Results are reported as hazard ratios (HR) with $95 \%$ confidence intervals $(95 \% \mathrm{CIs})$. A two-sided $\mathrm{p}$ value $<0.05$ was regarded as statistically significant.

The nomogram for PFS and OS of ES-SCLC was performed based on the results of multivariate survival analysis in the training cohort. The established nomogram was validated externally in the validation cohort using the "rms" package in $\mathrm{R}$ version 3.4.4. The nomogram performance was assessed using the Harrell's concordance index (c-index) and calibration curve. The c-index was calculated by bootstrapping with 100 samples to rank the discrimination, and calibration was achieved by generating a plot of the predicted survival probabilities against the actuarial outcome. Then, we used the likelihood ratio (LR) and Akaike information criterion (AIC) to evaluate the discriminatory ability and veracity of the nomogram models for prognostic factors. Decision curve analyses (DCA) were performed to calculate the clinical net benefit across a range of threshold probabilities for the models using the package of "stdca" in R. All statistical analyses were accomplished using SPSS (version 24.0; IBM Corp., Armonk, NY, USA) and R version 3.4.4 (R Foundation for Statistical Computing, Vienna, Austria) and figures were generated using Graphpad Prism 7 (GraphPad Software Inc., La Jolla, CA, USA).

\section{Results}

\section{Patient Characteristics}

With a median follow-up of 11.8 months, 148 and 66 patients in the training and validation cohorts, respectively, had died. Patient characteristic are shown in Table 1. None of the examined characteristics in validation cohort significantly differed from those of the training cohort $(\mathrm{p}>$ 0.05 ). The majority of patients in our study were male with smoking history, and $31.5 \%$ of patients in the training cohort and $36 \%$ of patients in the validation cohort received additional thoracic radiotherapy.

\section{Survival-Related Prognostic Factors and Multivariate Analyses in Training Cohort}

The median PFS of patients in the training cohort was 6.9 months (95\% CI 6.4-7.4 months), and the PFS rates at 6 
Table 4 Univariate and Multivariate Cox Models for OS in Training Cohort

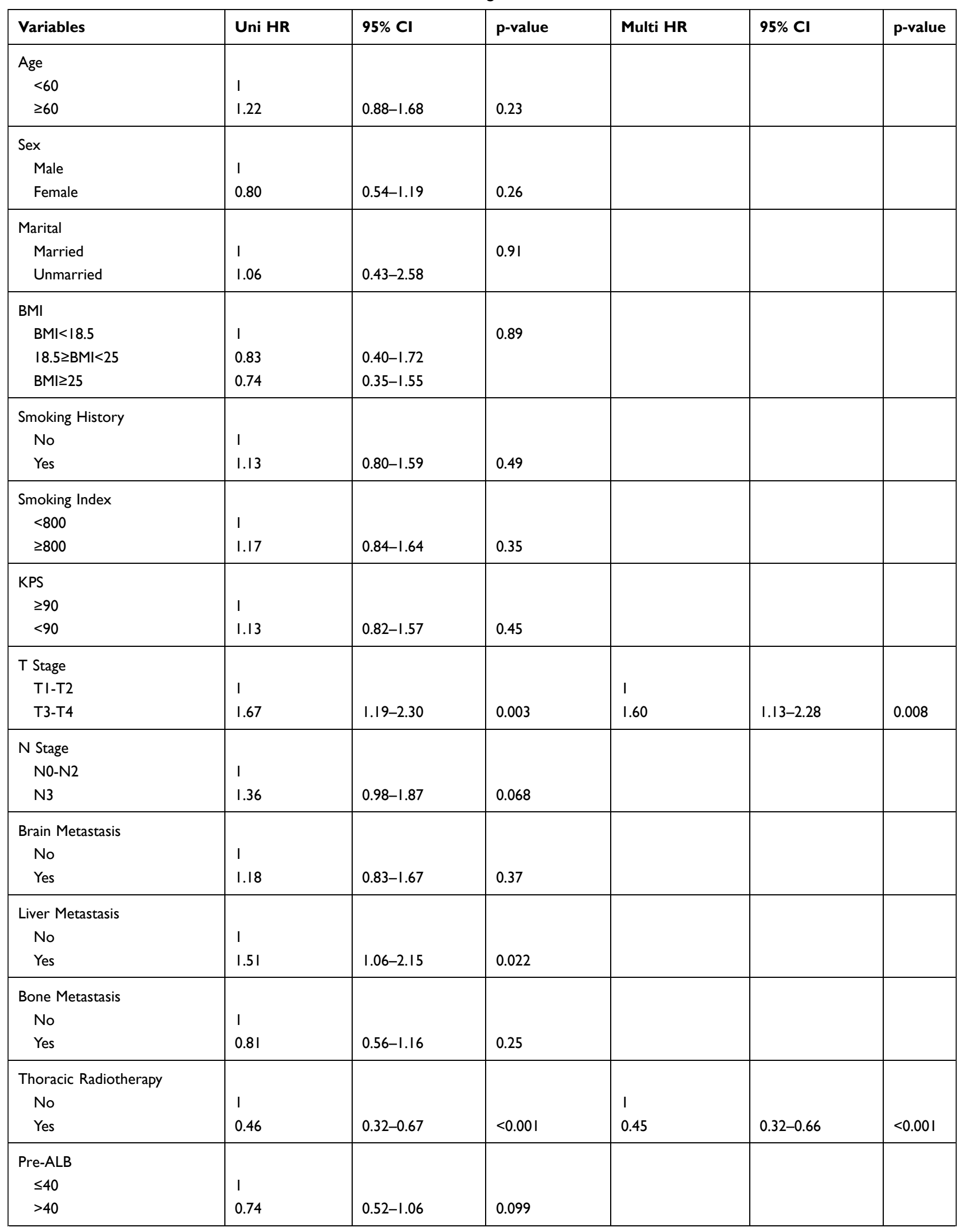

(Continued) 
Table 4 (Continued).

\begin{tabular}{|c|c|c|c|c|c|c|}
\hline Variables & Uni HR & $95 \% \mathrm{Cl}$ & p-value & Multi HR & $95 \% \mathrm{Cl}$ & p-value \\
\hline \multicolumn{7}{|l|}{ Pre-ALP } \\
\hline$\leq 100$ & I & & & & & \\
\hline$>100$ & 1.36 & $0.98-1.89$ & 0.064 & & & \\
\hline \multicolumn{7}{|l|}{ Pre-AAPR } \\
\hline$\leq 0.52$ & I & & & & & \\
\hline$>0.52$ & 0.64 & $0.46-0.91$ & 0.012 & & & \\
\hline \multicolumn{7}{|l|}{ Post-ALB } \\
\hline$\leq 40$ & I & & & & & \\
\hline$>40$ & 0.78 & $0.55-1.10$ & 0.153 & & & \\
\hline \multicolumn{7}{|l|}{ Post-ALP } \\
\hline$\leq 100$ & I & & & & & \\
\hline$>100$ & 1.49 & $1.04-2.12$ & 0.028 & & & \\
\hline \multicolumn{7}{|l|}{ Post-AAPR } \\
\hline$\leq 0.52$ & I & & & I & & \\
\hline$>0.52$ & 0.52 & $0.38-0.73$ & $<0.001$ & 0.62 & $0.44-0.86$ & 0.005 \\
\hline
\end{tabular}

Abbreviations: AAPR, albumin-to-alkaline phosphatase ratio; BMI, body mass index; HR, hazard ratios; KPS, Karnofsky performance score; OS, overall survival.

and 12 months were $59 \%$ and $13 \%$, respectively. The median OS of patients in the training cohort was 13.6 months (95\% CI 12.4-14.9 months), and the OS rates at 12 and 24 months were $48 \%$ and $17.5 \%$, respectively. In terms of correlation of AAPR and patient characteristic (Table 2), significant positive association was found between high level of pre-AAPR and liver metastasis in training cohort.

Univariate analyses revealed that T3-T4 stage, N3 stage, liver metastasis, lack of thoracic radiotherapy, high post-ALP level, and low pre-AAPR and post-AAPR levels were significant indices of disease progression. Multivariate analyses, identified three of these factors as independent negative predictors: $\mathrm{N} 3$ stage $(\mathrm{HR}=1.41$, 95\% CI 1.03-1.93, $\mathrm{p}=0.034$ ), without thoracic radiotherapy (HR $=0.4,95 \%$ CI $0.29-0.56, \mathrm{p}<0.001)$, and low post-AAPR levels ( $\mathrm{HR}=0.67,95 \%$ CI $0.49-0.92, \mathrm{p}=$ 0.013) (Table 3).

Assessment of OS in the training cohort revealed that T3-T4 stage, N3 stage, liver metastasis, without thoracic radiotherapy, high pre-ALP and post-ALP levels, and low pre-ALB, pre-AAPR, and post-AAPR levels were predictive of inferior OS. T stage ( $\mathrm{HR}=1.6,95 \%$ CI $1.13-2.28$, $\mathrm{p}=0.008)$, thoracic radiotherapy $(\mathrm{HR}=0.45,95 \% \mathrm{CI}$ $0.32-0.66, \mathrm{p}<0.001)$, and high post-AAPR (HR $=0.62$, $95 \%$ CI $0.44-0.86, \mathrm{p}=0.005$ ) were identified as independent risk factors for death (Table 4).
The independent PFS and OS risk factors were confirmed further using Kaplan-Meier analyses and were shown to have good prognostic capacity (Figures 1 and 2).

\section{Prognostic Nomogram for PFS and OS}

The prognostic nomogram for PFS and OS was established by the integration of independent significant factors in the training cohort (Figures $3 \mathrm{~A}$ and $4 \mathrm{~A}$ ), with c-indices of 0.675 and 0.662 , respectively. N-stage, thoracic radiotherapy, and post-AAPR were incorporated in the nomogram for PFS, and T-stage, thoracic radiotherapy and post-AAPR were incorporated in the nomogram for OS. The calibration plot revealed optimal consistency between the actual observation and the nomogrampredicted PFS and OS, for both the probability of PFS at 6 or 12 months (Figure 3B and C), and survival at 12 or 24 months (Figure 4B and C).

In the validation cohort, the median PFS was 6.9 months (95\% CI 5.9-7.9 months) and median OS was 16 months (95\% CI 13.8-18.1 months). The predictive accuracy of the established nomogram was further confirmed through external validation, with the c-indices of 0.697 and 0.664 for PFS and OS, respectively, in the validation cohort. PFS rates at 6 and 12 months were $64 \%$ and $12 \%$, respectively, and survival rates at 12 and 24 months were $49 \%$ and $13 \%$, respectively. The calibration plot illustrated the predictive probability of the established nomogram for 

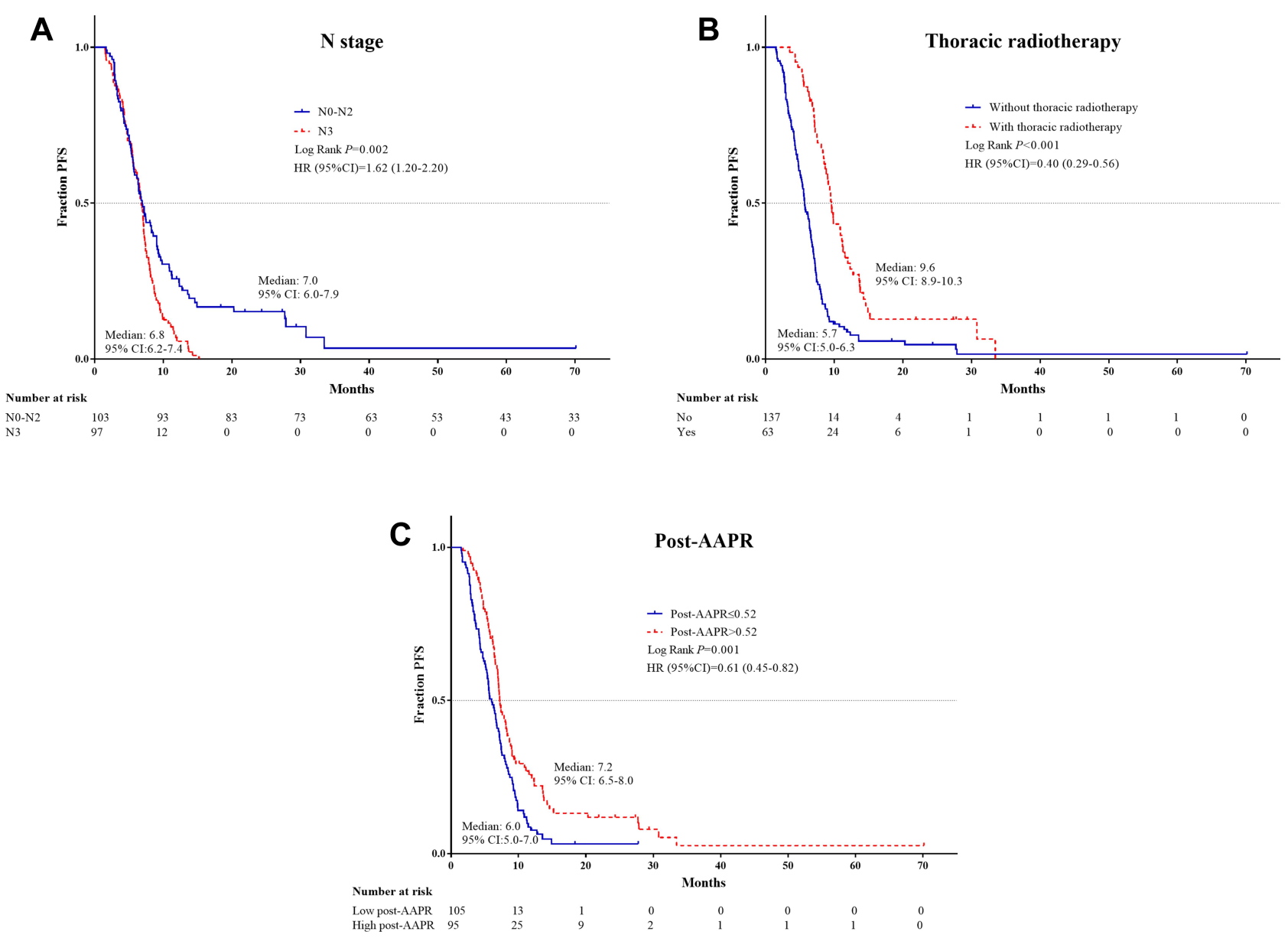

Figure I Kaplan-Meier survival plots of independent risk factors for PFS in ES-SCLC patients. (A) N stage; (B) Thoracic radiotherapy; (C) Post-AAPR. Abbreviations: PFS, progression-free survival; ES-SCLC, extensive-stage small-cell lung cancer; AAPR, albumin-to-alkaline phosphatase ratio.

PFS (Figure 3D and E) and OS (Figure 4D and E), with good agreement between observed and predicted values.

\section{Comparison of Predictive Ability of the Nomogram and TNM Stage}

To investigate the complementary role of dynamic AAPR in prognostic prediction, the prognostic abilities of TNM stage and the AAPR-TNM based nomogram were compared. DCA was performed to compare the potential clinical net benefit of the nomogram and TNM stage. Decision curves revealed that the nomogram had a greater net benefit for PFS and OS than did TNM stage (Figure 5). As shown in Table 5, the nomogram had significantly higher LRT $\chi^{2}$ and c-index values and significantly lower AIC values than the TNM staging system for PFS and OS, in both the training and validation cohorts $(\mathrm{p}<0.05)$.

TNM stage was also shown to have an outstanding capacity for both PFS and OS prognosis in the training and validation cohorts. The nomogram c-index value was significantly higher than that of the TNM stage $(0.539$ for PFS and 0.567 for OS, $p<0.05$ ) in the training cohort. The superiority of the prognostic ability of the nomogram was also demonstrated in the validation cohort with c-indices of 0.697 and 0.664 for PFS and OS, respectively, compared with 0.602 for PFS and 0.605 for OS for the TNM stage $(\mathrm{p}<0.05)$ (Figure 6). The nomogram has significantly higher LRT $\chi^{2}$ and lower AIC values for PFS and OS than did the TNM stage in both the training and validation cohorts (Table 5).

\section{Discussion}

SCLC is known as a lung cancer subtype with characteristics of invasiveness, rapid progression, and poor prognosis. The application of targeted therapy and immunotherapy has limited advantages for patients with SCLC,${ }^{27}$ and platinum-based chemotherapy for 4-6 cycles remains the first-line standard treatment. Therefore, it is essential to explore prognostic factors to identify high-risk 

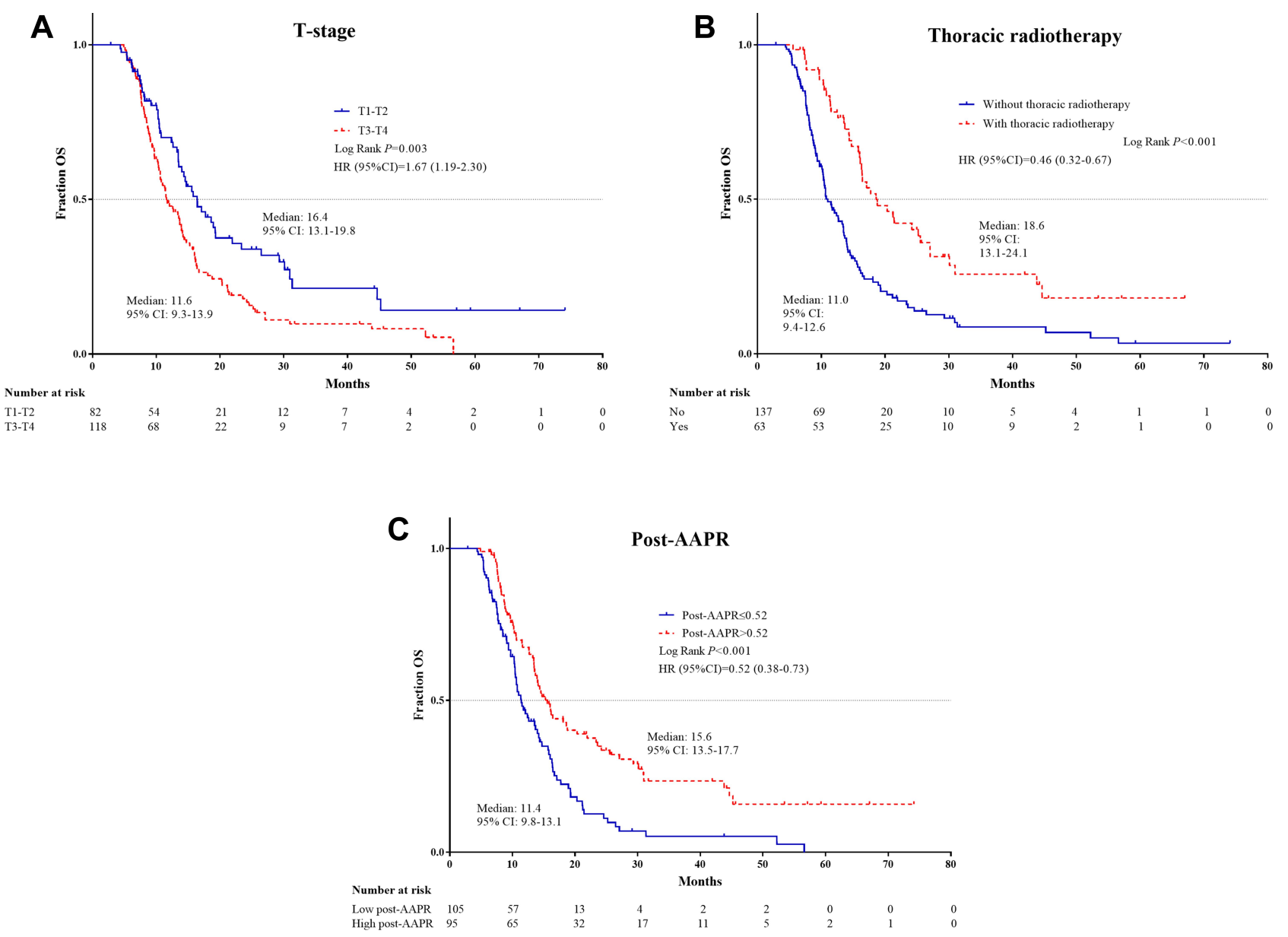

Figure 2 Kaplan-Meier survival plots of independent risk factors for OS in ES-SCLC patients. (A) T stage; (B) Thoracic radiotherapy; (C) Post-AAPR. Abbreviations: OS, overall survival; ES-SCLC, extensive-stage small-cell lung cancer; AAPR, albumin-to-alkaline phosphatase ratio.

A

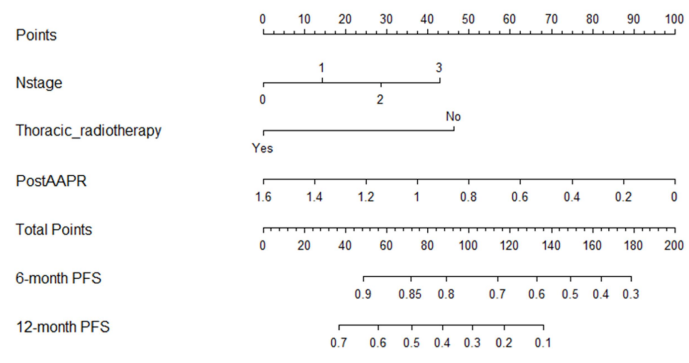

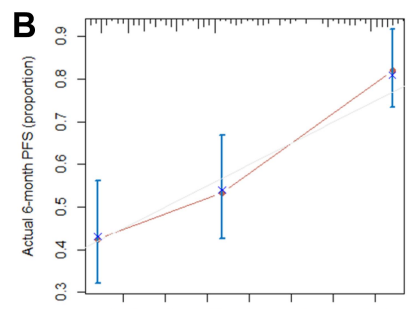

$\begin{array}{lllllll}0.45 & 0.50 & 0.55 & 0.60 & 0.65 & 0.70 & 0.75\end{array}$

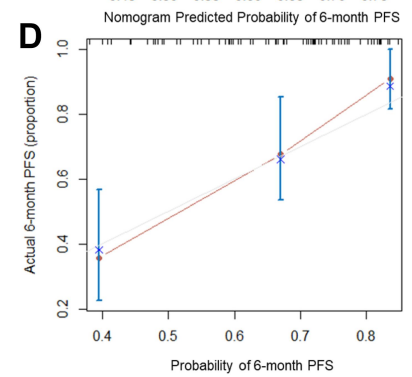

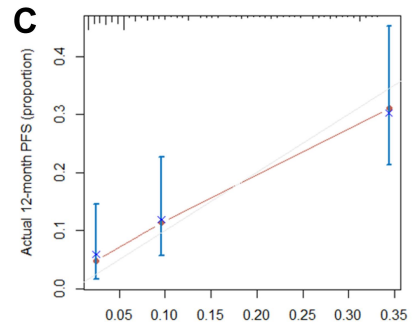

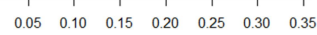

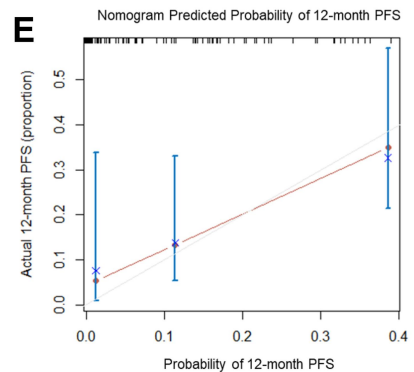

Figure 3 Nomogram and calibration curve for predicting PFS at 6- and 12-month for ES-SCLC patients. (A) Nomogram. The nomogram is used by adding the point identified on the points scale of each variable. The sum of points lies on the axis of Total Points, and corresponding to the percentage on the two axes at the bottom to indicate the 6- and I2-month PFS. (B) Calibration curve for 6-month PFS in training cohort; (C) Calibration curve for I2-month PFS in training cohort. (D) Calibration curve for 6-month PFS in validation cohort. (E) Calibration curve for 12-month PFS in validation cohort.

Abbreviations: PFS, progression-free survival; ES-SCLC, extensive-stage small-cell lung cancer; AAPR, albumin-to-alkaline phosphatase ratio. 
A

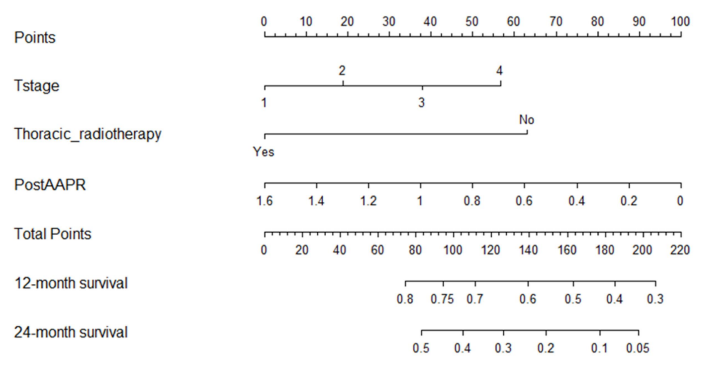

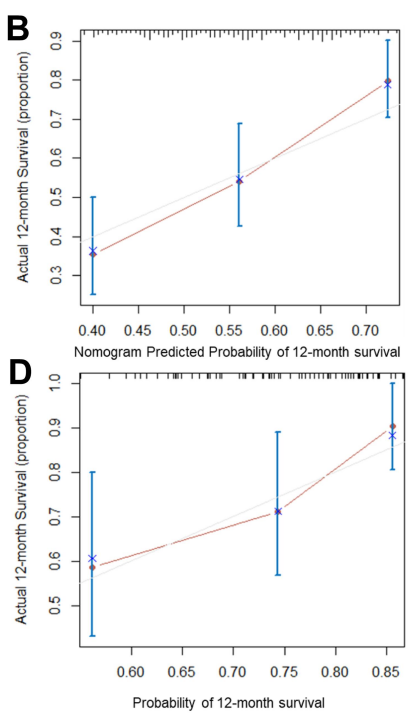

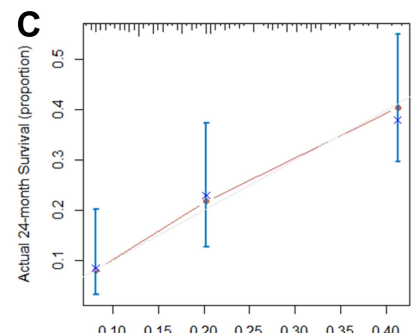

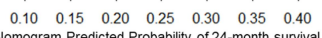

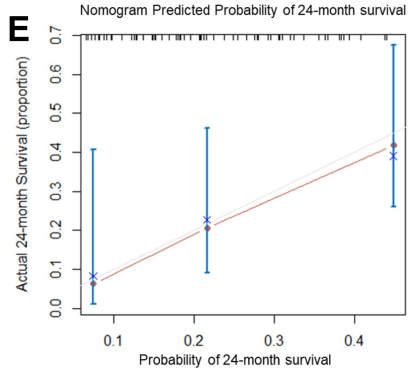

Figure 4 Nomogram and calibration curve for predicting OS at 12- and 24-month for ES-SCLC patients. (A) Nomogram; The nomogram is used by adding the point identified on the points scale of each variable. The sum of points lies on the axis of Total Points, and corresponding to the percentage on the two axes at the bottom to indicate the 12- and 24-month OS. (B) Calibration curve for 12-month OS in training cohort; (C) Calibration curve for 24-month OS in training cohort. (D) Calibration curve for 12-month OS in validation cohort. (E) Calibration curve for 24-month OS in validation cohort.

Abbreviations: OS, overall survival; ES-SCLC, extensive-stage small-cell lung cancer; AAPR, albumin-to-alkaline phosphatase ratio.

patients with SCLC. AAPR, a novel accessible and noninvasive hematological prognostic factor, is already used as a prognostic predictor in patients with hepatocellular, nasopharyngeal, and pancreatic carcinoma. Here, for the first time, we demonstrate that dynamic AAPR can be used for prognosis prediction in patients with ES-SCLC. Moreover, we developed and validated dynamic AAPRbased nomograms to quantitatively estimate survival in patients with ES-SCLC.

Although we have demonstrated the prognostic value of AAPR in patients with SCLC, the mechanisms underlying the prognostic value of AAPR remains unknown. Low ALB concentration is a marker of malnutrition in patients with cancer. ${ }^{28}$ Additionally, during inflammation, ALB is a negative acute phase protein. ALB levels decrease dramatically in response to acute phase protein demands through a combination of reduced production, increased degradation, and increased loss because of the high permeability of vessels. ${ }^{29,30}$ Therefore, low ALB levels also reflect the presence of inflammation in patients with cancer. Malnutrition and systemic inflammation are associated with inferior prognosis in patients with cancer. $^{31}$ Moreover, ALB is also involved in balancing cell proliferation and metabolism. ${ }^{32}$ ALP is a hydrolytic enzyme which can dephosphorylate multiple molecules including nucleotides. ${ }^{33}$ ALP functions to adjust purinergic signaling, which plays a role in the induction of inflammatory responses through ATP and ADP-mediated binding of nucleotide receptors. ${ }^{34}$ Additionally, inhibition of ALP activity reduces cancer cell viability and migration, and induces apoptosis. ${ }^{18}$ Therefore, AAPR is proposed to reflect systemic inflammation status and cell metabolism, and is associated with outcomes in patients with cancer. We also found that low pre-AAPR was associated with liver metastasis, because of the relationship between ALB, ALP, and liver function.

Low pre-AAPR could predict inferior PFS and OS in patients with ES-SCLC. This is consistent with results previously reported for patients with hepatocellular, nasopharyngeal, and pancreatic carcinoma. ${ }^{21,22,35}$ However, after multivariate analyses pre-AAPR lost the significance, and post-AAPR was an independent prognostic factor for PFS and OS. Tumor temporal heterogeneity means that either systemic or tumor status constantly changes during development and treatment. Our results show that low levels of post-AAPR, the indicator of inflammation, decreased nutritional status, and liver function during treatment, are valuable and informative in prognostic prediction. Therefore, a nomogram based on post-AAPR and incorporating other independent prognostic factors for PFS and OS was developed and compared with traditional TNM staging system.

Multivariate analyses revealed that patients with ESSCLC receiving additional thoracic radiotherapy had 

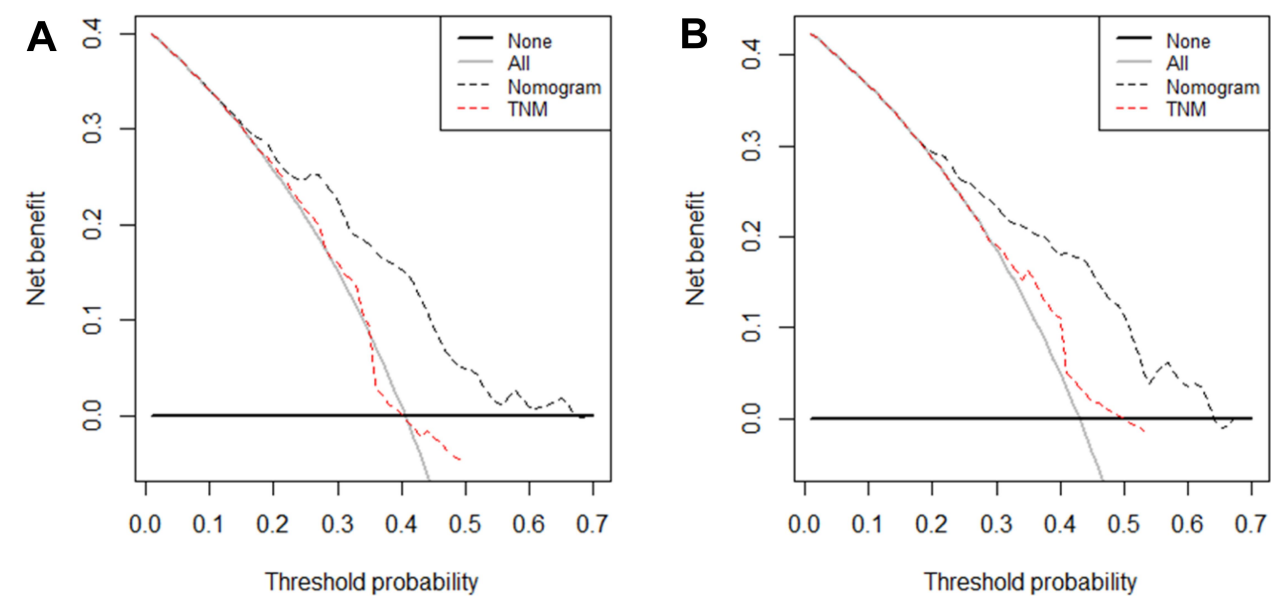

Figure 5 DCA of nomogram and TNM stage for prediction of PFS and OS of ES-SCLC patients. The dash line represents the net benefit of nomogram and TNM stage. (A) DCA of nomogram and TNM stage for prediction of 6-month PFS of ES-SCLC patients; (B) DCA of nomogram and TNM stage for prediction of I2-month OS of ES-SCLC patients. Abbreviations: PFS, progression-free survival; OS, overall survival; ES-SCLC, extensive-stage small-cell lung cancer.

superior PFS and OS with independent statistical significance. This is broadly in line with the results from randomized controlled trials ${ }^{36}$ and retrospective studies $^{37}$ of thoracic radiotherapy in patients with ES-SCLC. Our results also show the important role of TNM stage for prognosis and both $\mathrm{T}$ and $\mathrm{N}$ stage were found to be associated with PFS and OS. Multivariate survival analyses revealed that $\mathrm{N}$ stage remained an independent prognostic factor for PFS and that $\mathrm{T}$ stage remained an independent prognostic factor for OS.

Table 5 The Comparison of LRT $\chi^{2}$ and AIC for PFS and OS Between Nomogram and Prognostic Factors

\begin{tabular}{|c|c|c|c|c|}
\hline & $\begin{array}{l}\text { LRT } \\
\chi^{2}\end{array}$ & c-Index & AIC & p-value \\
\hline \multicolumn{5}{|l|}{ Training cohort for } \\
\hline \multicolumn{5}{|l|}{ PFS } \\
\hline TNM stage & 10.83 & 0.539 & 1589.2 & 0.004 \\
\hline Nomogram & 49.35 & 0.675 & 1553.6 & $<0.001$ \\
\hline \multirow{2}{*}{\multicolumn{5}{|c|}{$\begin{array}{l}\text { Validation cohort for } \\
\text { PFS }\end{array}$}} \\
\hline & & & & \\
\hline TNM stage & 8.02 & 0.602 & 632.7 & 0.02 \\
\hline Nomogram & 21.07 & 0.697 & 620.88 & $<0.001$ \\
\hline \multicolumn{5}{|l|}{ Training cohort for OS } \\
\hline TNM stage & 8.85 & 0.567 & 1310.7 & 0.01 \\
\hline Nomogram & 34.36 & 0.662 & 1287.2 & $<0.001$ \\
\hline \multicolumn{5}{|l|}{ Validation cohort for } \\
\hline \multicolumn{5}{|l|}{ OS } \\
\hline TNM stage & 8.30 & 0.605 & 474.1 & 0.02 \\
\hline Nomogram & 16.09 & 0.664 & 468.32 & $<0.001$ \\
\hline
\end{tabular}

Abbreviations: LR, likelihood ratio; AIC, Akaike information criterion.

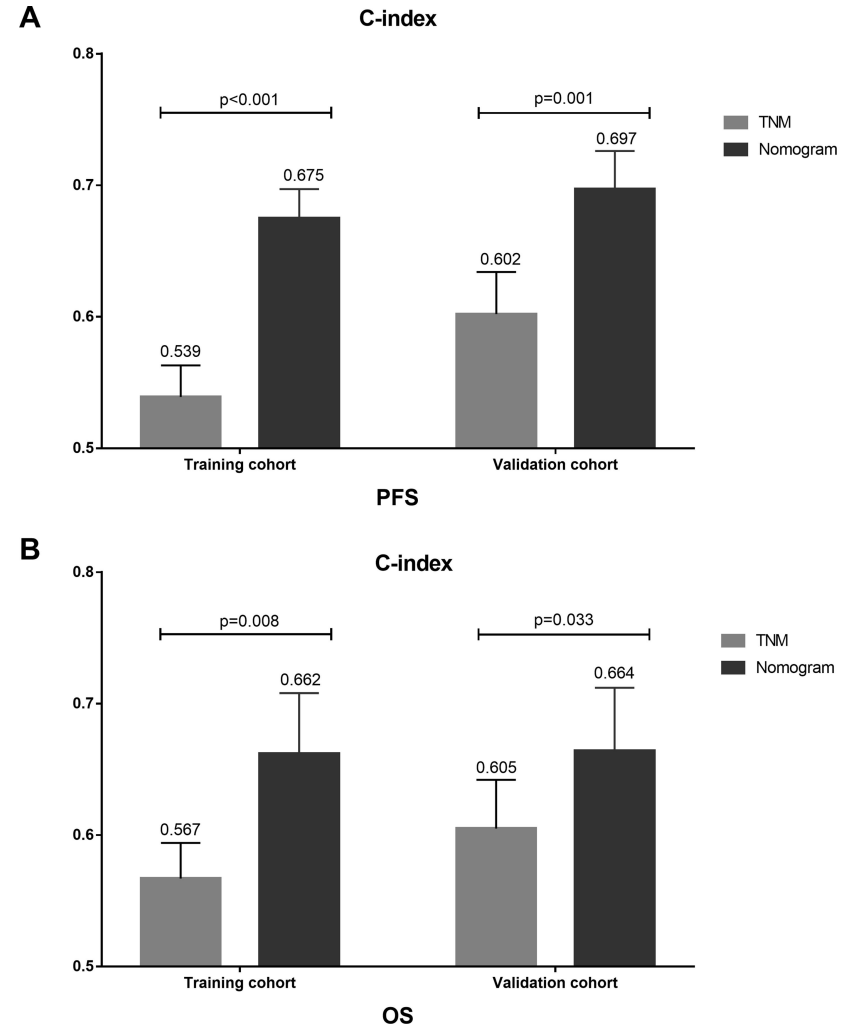

Figure 6 The comparison of c-index of TNM and nomogram for PFS and OS in training cohort and validation cohort, respectively. (A) The c-index of TNM and nomogram for PFS in training cohort $(0.539$ vs. $0.675, p<0.001)$ and validation cohort ( 0.602 vs. $0.697, p=0.001)$. (B) The c-index of TNM and nomogram for OS in training cohort (0.567 vs. $0.662, p=0.009)$ and validation cohort $(0.605$ vs. $0.664, p=0.033)$. Abbreviations: PFS, progression-free survival; OS, overall survival.

Here, for the first time, we included post-AAPR, rather than baseline AAPR, and established a dynamic AAPR-based nomogram for prognosis prediction in patients with ES-SCLC. We then confirmed that dynamic AAPR is both superior and 
complementary to the TNM staging system in prognosis prediction in these patients. The TNM staging system is based on the level of tumor burden and involves knowledge of the size or direct extent of the primary tumor, the spread to regional lymph nodes, and the presence of distant metastasis. Given the heterogeneity of the tumor micro-environment, patient characteristics, and treatments, there is a great deal of variation in outcomes among patients with same TNM stage. Increasing numbers of studies have demonstrated that information from distinct sources contribute to a more accurate prediction model. ${ }^{38}$ In our study, the post-AAPR-based nomogram integrated information about dynamic tumor and systemic status changes, treatment heterogeneity, and tumor burden. The superior performance of the nomogram compared to TNM stage was validated in the validation cohort. Therefore, we constructed a comprehensive and dynamic nomogram with the characteristic of non-invasion, and the potential role of the nomogram on clinical individual therapy was indicated by DCA results.

However, there are some limitations in our study. Firstly, this is a retrospective study from a single center which may cause selection bias, which we tried to minimize by establishing training and validation cohorts. Even if our study included information from distinct sources, other potential prognostic markers, which may have additional value, were not available for our nomogram. Therefore, this AAPR-based nomogram requires further validation and extension in a random, prospective study with a larger number of patients. Furthermore, the mechanisms underlying the prognostic role of dynamic AAPR remain to be further elucidated.

\section{Conclusion}

We have identified post-AAPR as a prognostic factor for patients with ES-SCLC, and recommend AAPR to be dynamically evaluated to guide patient treatment. Our post-AAPR nomogram accurately predicts individual survival probability and could be used as a tool for clinical decision-making.

\section{Abbreviations}

SCLC, small-cell lung cancer; PFS, progression-free survival; OS, overall survival; ALB, albumin; ALP, alkaline phosphatase; AAPR, albumin-to-alkaline phosphatase ratio; VALSG, Veterans Administration Lung Study Group; LSSCLC, limited-stage SCLC; ES-SCLC, extensive-stage SCLC; BMI, body mass index; KPS, Karnofsky performance score; RECIST, Response Evaluation Criteria in Solid Tumors; ROC, receiver operating characteristic curve; HR, hazard ratios; $\mathrm{CI}$, confidence intervals; $\mathrm{C}$-index, concordance index; LR, likelihood ratio; AIC, Akaike information criterion; DCA, decision curve analyses.

\section{Data Sharing Statement}

The data in this study are available from the corresponding author upon reasonable request.

\section{Ethical Approval and Informed Consent}

This study was approved by the Ethics Committee of Shandong Cancer Hospital and Institute (No. SDTH EC201808005).

\section{Author Contributions}

All authors made substantial contributions to conception and design, acquisition of data, or analysis and interpretation of data; took part in drafting the article or revising it critically for important intellectual content; gave final approval of the version to be published; and agree to be accountable for all aspects of the work.

\section{Funding}

This work was supported by the following grant: The Project of Postdoctoral Innovation of Shandong Province (Grant No. 201501010 and 201601006), the Project of Postdoctoral Science Foundation of China (Grant No. 2016M590640) and National Natural Science Foundation of China (Grant No. 815026).

\section{Disclosure}

The authors report no conflicts of interest for this work.

\section{References}

1. Herbst RS, Heymach JV, Lippman SM. Lung cancer. $N$ Engl J Med. 2008;359(13):1367-1380. doi:10.1056/NEJMra0802714

2. van Meerbeeck JP, Fennell DA, De Ruysscher DK. Small-cell lung cancer. Lancet (London, England). 2011;378(9804):1741-1755. doi:10.1016/S0140-6736(11)60165-7

3. Hirsch FR, Scagliotti GV, Mulshine JL, et al. Lung cancer: current therapies and new targeted treatments. Lancet (London, England). 2017;389(10066):299-311. doi:10.1016/S0140-6736(16)30958-8

4. Osmani L, Askin F, Gabrielson E, Li QK. Current WHO guidelines and the critical role of immunohistochemical markers in the subclassification of non-small cell lung carcinoma (NSCLC): moving from targeted therapy to immunotherapy. Semin Cancer Biol. 2018;52(Pt 1):103-109. doi:10.1016/j.semcancer.2017.11.019

5. Saito M, Shiraishi K, Goto A, Suzuki H, Kohno T, Kono K. Development of targeted therapy and immunotherapy for treatment of small cell lung cancer. Jpn J Clin Oncol. 2018;48(7):603-608. doi:10.1093/jjco/hyy068 
6. Horn L, Mansfield AS, Szczesna A, et al. First-line atezolizumab plus chemotherapy in extensive-stage small-cell lung cancer. $N$ Engl J Med. 2018;379(23):2220-2229. doi:10.1056/NEJMoa180 9064

7. Lara PN Jr., Natale R, Crowley J, et al. Phase III trial of irinotecan/ cisplatin compared with etoposide/cisplatin in extensive-stage small-cell lung cancer: clinical and pharmacogenomic results from SWOG S0124. J Clin Oncol. 2009;27(15):2530-2535. doi:10.1200/ JCO.2008.20.1061

8. Chan BA, Coward JI. Chemotherapy advances in small-cell lung cancer. J Thorac Dis. 2013;5(Suppl 5):S565-S578. doi:10.3978/j. issn.2072-1439.2013.07.43

9. Lu H, Ouyang W, Huang C. Inflammation, a key event in cancer development. Mol Cancer Res. 2006;4(4):221-233. doi:10.1158/ 1541-7786.MCR-05-0261

10. Don BR, Kaysen G. Poor nutritional status and inflammation: serum albumin: relationship to inflammation and nutrition. Semin Dial. 2004;17(6):432-437. doi:10.1111/j.0894-0959.2004.17603.x

11. Boonpipattanapong T, Chewatanakornkul S. Preoperative carcinoembryonic antigen and albumin in predicting survival in patients with colon and rectal carcinomas. J Clin Gastroenterol. 2006;40 (7):592-595. doi:10.1097/00004836-200608000-00006

12. Hsu S-N, Hsu Y-J, Lin C, Su S-L, Lin S-H. Proteinuria: associated with poor outcome in patients with small cell lung cancer. $J$ Cancer Res Ther. 2018;14(10):688-693. doi:10.4103/0973-1482.191037

13. Lis CG, Grutsch JF, Vashi PG, Lammersfeld CA. Is serum albumin an independent predictor of survival in patients with breast cancer? JPEN J Parenter Enteral Nutr. 2003;27(1):10-15. doi:10.1177/ 014860710302700110

14. Onate-Ocana LF, Aiello-Crocifoglio V, Gallardo-Rincon D, et al. Serum albumin as a significant prognostic factor for patients with gastric carcinoma. Ann Surg Oncol. 2007;14(2):381-389. doi:10.1245/s10434-006-9093-X

15. Rupp C, Stiehl A, Trauner M, Gotthardt DN. Editorial: further evidence for the role of serum alkaline phosphatase as a useful surrogate marker of prognosis in PSC - authors' reply. Aliment Pharmacol Ther. 2015;41(1):151-152. doi:10.1111/apt.13020

16. Damera S, Raphael KL, Baird BC, Cheung AK, Greene T, Beddhu S. Serum alkaline phosphatase levels associate with elevated serum C-reactive protein in chronic kidney disease. Kidney Int. 2011;79 (2):228-233. doi:10.1038/ki.2010.356

17. Lim SM, Kim YN, Park KH, et al. Bone alkaline phosphatase as a surrogate marker of bone metastasis in gastric cancer patients. $B M C$ Cancer. 2016;16:385. doi:10.1186/s12885-016-2415-x

18. Rao SR, Snaith AE, Marino D, et al. Tumour-derived alkaline phosphatase regulates tumour growth, epithelial plasticity and disease-free survival in metastatic prostate cancer. Br J Cancer. 2017;116 (2):227-236. doi:10.1038/bjc.2016.402

19. Rader BA. Alkaline phosphatase, an unconventional immune protein. Front Immunol. 2017;8:897. doi:10.3389/fimmu.2017.00897

20. Kuroda D, Sawayama H, Kurashige J, et al. Controlling Nutritional Status (CONUT) score is a prognostic marker for gastric cancer patients after curative resection. Gastric Cancer. 2018;21 (2):204-212. doi:10.1007/s10120-017-0744-3

21. Cai X, Chen Z, Chen J, et al. Albumin-to-alkaline phosphatase ratio as an independent prognostic factor for overall survival of advanced hepatocellular carcinoma patients without receiving standard anti-cancer therapies. J Cancer. 2018;9(1):189-197. doi:10.7150/ jca.21799

22. Nie M, Sun P, Chen C, et al. Albumin-to-alkaline phosphatase ratio: a novel prognostic index of overall survival in cisplatin-based chemotherapy-treated patients with metastatic nasopharyngeal carcinoma. J Cancer. 2017;8(5):809-815. doi:10.7150/ jca. 17536
23. Jhun BW, Lee KJ, Jeon $\mathrm{K}$, et al. Clinical applicability of staging small cell lung cancer according to the seventh edition of the TNM staging system. Lung Cancer. 2013;81(1):65-70. doi:10.1016/j. lungcan.2013.03.005

24. Liang W, Zhang L, Jiang G, et al. Development and validation of a nomogram for predicting survival in patients with resected non-small-cell lung cancer. J Clin Oncol. 2015;33(8):861-869. doi:10.1200/JCO.2014.56.6661

25. Li S, Zhao J, Zhu L, Su F, Chen K. Development and validation of a nomogram predicting the overall survival of stage IV breast cancer patients. Cancer Med. 2017;6(11):2586-2594. doi:10.1002/cam4. 1224

26. Necchi A, Sonpavde G, Lo Vullo S, et al. Nomogram-based prediction of overall survival in patients with metastatic urothelial carcinoma receiving first-line platinum-based chemotherapy: retrospective international study of invasive/advanced cancer of the urothelium (RISC). Eur Urol. 2017;71(2):281-289. doi:10.1016/j.eururo.2016. 09.042

27. Ferrara R, Mezquita L, Besse B. Progress in the management of advanced thoracic malignancies in 2017. J Thorac Dis. 2018;13 (3):301-322. doi:10.1016/j.jtho.2018.01.002

28. McIntosh EN, Laurent LL. Nutritional assessment of the hospitalized patient. Am Fam Physician. 1983;27(1):169-175.

29. Ishizuka M, Nagata H, Takagi K, Horie T, Kubota K. Inflammationbased prognostic score is a novel predictor of postoperative outcome in patients with colorectal cancer. Ann Surg. 2007;246(6):1047-1051. doi:10.1097/SLA.0b013e3181454171

30. de Mutsert R, Grootendorst DC, Indemans F, Boeschoten EW, Krediet RT, Dekker FW. Association between serum albumin and mortality in dialysis patients is partly explained by inflammation, and not by malnutrition. J Renal Nutr. 2009;19(2):127-135. doi:10.1053/ j.jrn.2008.08.003

31. Lamb GWA, Aitchison M, Ramsey S, Housley SL, Mcmillan DC. Clinical utility of the Glasgow Prognostic Score in patients undergoing curative nephrectomy for renal clear cell cancer: basis of new prognostic scoring systems. Br J Cancer. 2012;106(2):279-283. doi:10.1038/bjc.2011.556

32. Nojiri S, Joh T. Albumin suppresses human hepatocellular carcinoma proliferation and the cell cycle. Int J Mol Sci. 2014;15(3):5163-5174. doi:10.3390/ijms 15035163

33. Cauwels A, Rogge E, Vandendriessche B, Shiva S, Brouckaert P. Extracellular ATP drives systemic inflammation, tissue damage and mortality. Cell Death Dis. 2014;5:e1102. doi:10.1038/cddis.2014.70

34. Peters E, Geraci S, Heemskerk S, et al. Alkaline phosphatase protects against renal inflammation through dephosphorylation of lipopolysaccharide and adenosine triphosphate. Br J Pharmacol. 2015;172 (20):4932-4945. doi:10.1111/bph.13261

35. Pu N, Gao S, Xu Y, et al. Alkaline phosphatase-to-albumin ratio as a prognostic indicator in pancreatic ductal adenocarcinoma after curative resection. J Cancer. 2017;8(16):3362-3370. doi:10.7150/ jca.20917

36. Slotman BJ, van Tinteren H, Praag JO, et al. Use of thoracic radiotherapy for extensive stage small-cell lung cancer: a Phase 3 randomised controlled trial. Lancet. 2015;385(9962):36-42. doi:10.1016/ S0140-6736(14)61085-0

37. Li-Ming X, Zhao LJ, Simone CB 2nd, et al. Receipt of thoracic radiation therapy and radiotherapy dose are correlated with outcomes in a retrospective study of three hundred and six patients with extensive stage small-cell lung cancer. Radiother Oncol. 2017;125 (2):331-337. doi:10.1016/j.radonc.2017.10.005

38. Wang S, Yang L, Ci B, et al. Development and validation of a nomogram prognostic model for SCLC patients. J Thorac Dis. 2018;13(9):1338-1348. doi:10.1016/j.jtho.2018.05.037 


\section{Publish your work in this journal}

OncoTargets and Therapy is an international, peer-reviewed, open access journal focusing on the pathological basis of all cancers, potential targets for therapy and treatment protocols employed to improve the management of cancer patients. The journal also focuses on the impact of management programs and new therapeutic

Submit your manuscript here: https://www.dovepress.com/oncotargets-and-therapy-journa agents and protocols on patient perspectives such as quality of life, adherence and satisfaction. The manuscript management system is completely online and includes a very quick and fair peer-review system, which is all easy to use. Visit http://www.dovepress.com/ testimonials.php to read real quotes from published authors. 